\title{
RESENHA
}

\section{A MEMÓRIA PARTILHADA}

Resenha de: Bosi, Ecléa. (2003). O Tempo Vivo da Memória: Ensaios de Psicologia Social. São Paulo: Ateliê Editorial.

este livro de admirável sensibilidade humana, Ecléa Bosi explora o
campo de experiência pessoal com os eventos do dia-a-dia, registrados na lembrança, contados para outrem. Não é a memória que se tranca em sí mesma, mas a que partilha seus conteúdos quando há um ouvido disponível e atento, e que os define, no próprio ato de contar. Há uma história oficial, a dos manuais e das datas importantes que todos nós quando estudantes, e sob protesto, tivemos de decorar. A a que se refere Ecléa é outra história, a de cada um, construída ao longo da vida, a partir de um cotidiano muitas vezes corriqueiro mas sempre relevante.

A toda hora, somos capazes de recuperar aspectos de nosso passado: é como se nos contássemos histórias a nós-mesmos, alguns chegam a registrálas em forma de diário. Mas o relato primordial é o que pode ser feito a outras pessoas: através dele, o que vivemos e que é bem nosso ganha uma dimensão social, obtém testemunhas (mesmo que a posteriori), faz com que os outros ampliem sua experiência, através das nossas palavras. Há troca e cumplicidade. Viver, para Contar (a vida), o título das memórias de Gabriel García Márques, serve para todos nós. Viver algo notável gera a necessidade de contar: você sabe o que eu vi? você sabe o que me aconteceu ? E tudo o que nos acontece é notável porque nos concerne. É interessante notar que estudiosos supõem ter a linguagem se originado, em nossa espécie, a partir da representação de situações sociais; talvez se possa dizer, parafraseando García Márquez, que se nos lembramos é para poder contar. 
Falar nem sempre é pragmático, no sentido de coordenar a ação sobre o mundo, falar aproxima as pessoas e as coloca num campo de significados comuns. É um contacto de experiências no qual tomamos um prazer especial (não nos definiu o psicólogo Dunbarcomo uma espécie palradora, em que os relacionamentos sociais se reforçam através do bate-papo ?), graças ao qual reduzimos a solidão à qual nos condena a nossa individualidade e os mundos próprios que construimos para nós-mesmos. Não se trata de uma memória-hábito, mas uma memória de eventos únicos, uma memória bergsoniana das coisas em constante transformação, da qual nos fala Ecléa.

Digo "nos fala" porque o tom do relato é que marca a maneira de Ecléa compor os ensaios que fazem parte do livro. Ela escreve como quem conta, vai acrescentando as idéias em pequenas frases sempre dentro da linha narrativa e a gente lê com a sensação de que está na presença de fatos de uma experiência que também poderia ser nossa. Ecléa não se esconde atrás do que diz, em formalidade desnecessária (mesmo quando, às vezes, escreve como quem dá uma aula), seu texto remete aos trajetos seguidos, aos engajamentos pessoais que o originaram. "Durante anos sucessivos meu alunos de Psicologia Social... representaram a novela "O Capote" de Nicolai Cogol" (p. 127) ou "Faz alguns anos recolhi a memória do tempo... a memória do trabalho de velhos moradores de São Paulo" (p. 69).

Perpassa o texto um senso poético especial. Ecléa tem talento para captar o pormenor, redimindo e dignificando o cotidiano. É assim que se refere, de forma suave, à paz da cidade, quando cai a noite: "A seqüência de movimentos na calçada segue ritmos que aceleram e se abrandam em horas certas e vão se extinguindo devagar quando as janelas se iluminam e as ruas se esvaziam. Depois, as janelas vão-se apagando e fechando, menos alguma que resiste ainda, da qual escapa um som que finalmente silencia" (p. 72).; e é assim que, graças a uma imagem que nos surpreende, infunde força de transformação àquilo que parece ter a eternidade do concreto: "[o bairro tem] sua infância, juventude, velhice... as casas crescem do chão e vão mudando: canteiros, cercas, muros, escadas, cores novas, a terra vermelha e depois o verde umbroso. Arbustos e depois árvores, calçadas, esquinas... uma casa pintada de azul que irradia a luz da manhã, os terrenos baldios, as 
ruas sem saída que terminam em praças ermas... o bairro acompanha o ritmo da respiração e da vida dos seus moradores. Suas histórias se misturam e nós começamos a enxergar nas ruas o que nunca viríamos, mas nos contaram" (pp. 73-74). E é assim que fala dos simples sobrados "que não merecem tombamento porque lá não morou nenhum barão, mas foram adquiridos com prestações custosas, privações sem fim, que resultaram nessas casas adoráveis que conhecemos: a máquina de costura a um canto da sala, a TV redimida por uma toalha de crochê, os gerânios. Salas onde a gente ficaria um século escutando, onde as meias paredes filtram conversas, exercícios de piano, a água correndo, a canção dominical (se faz sol)" (p. 74).

A memória traduzida em palavras e que transmite uma experiência vivida tem interesse enorme para o psicólogo. Através dela, ele pode ter acesso aos momentos de antigamente que permanecem, mesmo que sem que deles se tome consciência, como motivos para o comportamento presente. Durante uma época, em minha carreira, me interessei pelo que se convencionou chamar, na área experimental, memória autobiográfica: o enfoque não era contudo fenomenológico, visava à compreensão dos processos básicos da retenção. Os psicólogos da memória reservam, com muito acerto, um capítulo à parte para as lembranças de eventos que cada um vive como seus, em contraste com aquelas relacionadas ao modo de fazer e aos princípios gerais. Em nossas pesquisas, pedíamos que, durante alguns dias, pessoas mantivessem um diário; depois, verificávamos que conteúdos perduravam na memória, depois de intervalos mais ou menos longos. Pensávemos, partindo do pressuposto psicanalítico de que há repressão de conteúdos conflituosos, que as lembranças de eventos positivos teriam preeminência na le mbrança. Mas não. Fossem os eventos agradáveis ou penosos, a sua permanência na memória dependia do quanto tinham de impacto afetivo. Eventos que não provocavam medo, humilhação, expectativa, alegria, ou seja, que não mexiam com a pessoa, eram mais facilmente relegados ao esquecimento. A capacidade que a emoção tem de priorizar certos conteúdo da memória autobiográfica me parece digna de nota por mostrar que, pelo menos nesta área, não é viável uma explicação puramente cognitiva. 
Mas a perspectiva na qual se coloca Ecléa transcende, sem abandonála, a perspectiva individual. Cada relato remete a situações em que o depoente se envolveu em interação com outras pessoas, reflete as crenças que adquiriu em seu grupo, se ancora temporalmente aos eventos que fizeram notícia e qualificaram a época, sobre campeonatos de futebol, sobre acidentes e crimes, sobre escândalos e política (sem querer associar ambos, embora...), sobre a passagem do cometa Halley, sobre a marcha das mulheres pela família e pela propriedade, sobre o movimento das diretas já, sobre o impeachment do presidente Collor, sobre o atentado do 11 de setembro etc. A vida "privada" constitui o testemunho de um tempo coletivo, e o psicólogo social pode remontar, a partir das práticas da privacidade, para o contexto social do qual se nutrem e que elas ajudam a definir. Nesta empresa, a psicologia estabelece zonas de transição e de interdisciplinaridade com a história e as outras ciências sociais.

Acho preciosas e reveladoras as "sugestões para um jovem pesquisador" (cartas a um jovem poeta?) que Ecléa dá, a partir de intuições cultivadas ao longo de anos de pesquisa, em contextos diversos, mas sempre centradas no encontro e na criação de interações privilegiadas. Não são as regras que um capítulo de metodologia costuma conter e não se preocupam com a quantificação das coisas. São práticas num outro sentido. Lembram o quanto é essencial criar um contexto de confiança e de apego para poder aproximar-se dos modos como alguém se vê e vê os eventos nos quais tomou parte. Trata-se de um exercício de alteridade. Não há nada que eu ache mais impressionante a respeito da consciência humana do que esta capacidade que temos - se houver o desejo e se forem propícias as condições - de apreender o jeito de os outros serem, adotando por um momento sua perspectiva, decentrando nossa percepção, como diria Piaget.

Quais são as dicas que Ecléa propõe? Em primeiro lugar, obter informações objetivas a respeito do assunto de que irá falar o depoente, assim não estaremos metendo os pés pelas mãos a respeito da história e da geografia das coisas que serão relatadas. Em seguida, efetuar uma aproximação pessoal aos contextos aos quais ele pertence, indo, se possível à sua casa, e "sair com ele, caminhar ao seu lado nos lugares em que os episódios lem- 
brados ocorreram" (p. 60), (este andar, evidentemente, pode ser virtual, se os eventos relatados forem distantes, no tempo, no espaço). Cabe efetuar uma conversa prévia (ou pré-entrevista, mas não fica claro o quanto o "pré" já não é começo) para adquirimos informação a respeito do que constitui o cerne de suas preocupações, dos termos que usa e do modo de reconstituir o passado que é bem dele. E, sobretudo, formar laços de amizade. Estes laços são tão necessários quanto inevitáveis. Ocorrem porque, ao perguntarmos sobre o passado do depoente, estamos nos colocando na posição de pessoa que se interessa por ele e quer partilhar a sua experiência. É a aventura conjunta de reviver e o que fala implicitamente agradece ao que escuta, por terlhe fornecido uma oportunidade para saber o que tinha a dizer (não afirma Alain que precisamos de palavras para saber o que pensamos?).

Tudo tem de ser anotado. Reencontro, nesta sugestão de Ecléa, minha própria alegria de naturalista, sempre pronto a registrar o muito que pode ser visto. A manutenção de um diário, na pesquisa sobre memórias, salva, na memória do pesquisador, os pormenores que apenas na aparência e à consciência apressada são irrelevantes. Sugiro sempre aos meus alunos que, quando possível, gravem suas entrevistas: ouvir depois é descobrir a riqueza das nuances, dos silêncios, das reticências, daquilo que não se pretendia talvez transmitir mas que passou assim mesmo. Ecléa ressalta a importância das hesitações e dos silêncios. "Os lapsos e incertezas das testemunhas são o selo da autenticidade... A fala emotiva e fragmentada é portadora de significações que nos aproximam da verdade. Aprendemos a amar esse discurso tateante, suas pausas, suas franjas com fios perdidos quase irreparáveis" (pp. 63-65). No trabalho de colher um depoimento, com atenção "intensa e leve", cabe perceber a forma como o depoente ordena as suas lembranças, os aspectos da narrativa que ele ressalta, os que ele deixa mais pobres, os momentos de transição nos quais se revelam as passagens de sua vida. E os seus esquecimentos. Tudo serve para que surja um campo global de significação, extraído dos muitos fragmentos colhidos, numa totalidade que Ecléa qualifica de gestáltica. Finalmente, mais do que uma sugestão, um ponto ético: mostrar o depoimento, depois de transcrito, a quem o deu, para que 
possa apreciá-lo e tenha a liberdade de modificá-lo. É o que muitas vezes não fazem os jornalistas científicos quando nos pedem uma entrevista !

Não há porque exigir do relato que tenha precisão histórica. Ele tem a sua própria verdade, que é a da crença e da atitude. Temos que tomá-lo como dado, notar as suas contradições, seus vièses, seus limites, interpretá-lo. Ir além dele para reencontrar a sua coerência. Constata Ecléa, com desapontamento, que contar é trair a experiência imediata. "É verdade que, ao narrar uma experiência profunda, nós a perdemos também, naquele momento em que ela se corporifica (e enrijece) na narrativa" (p. 35). E mais: "difícil é o caminho de volta às coisas, de volta ao mundo da vida pré-categorial e préreflexiva, para reendontrar os fenômenos face a face" (p. 116). Trata-se de uma dificuldade metafísica, análoga à que encontram os filósofos quando buscam definir as características íntimas da consciência, ou qualia. Tem a ver com a esquematização necessária que a linguagem impõe aos "dados imediatos da consciência". Não vejo como dela escapar: a linguagem (e a sua rigidez) é o preço que temos de pagar para criar campos partilhados de significado. Se é que perdemos o contato face a face com os fenômenos é porque precisamos ficar face a face com os outros.

Uma certa distração contribui para empobrecer o relato e nos tornar passivos em relação às verdades fáceis do consenso. "Nem sempre estamos dispostos à aventura da percepção, somos insensíveis e desatentos às coisas que povoam o nosso mundo e, por isso, sofremos de uma perda... que nos faz capitular e enxergar através de mediações impostas" (p. 115). Aqui reside o perigo maior: assimilar categorias que nos foram vendidas, ou impostas, que adotadamos sem crítica, por conveniência, por medo, para não sermos diferentes, para nos colocarmos do lado dos mais fortes. Tão profundamente as assimilamos que as tomamos por categorias objetivas. Rica e criativa como é, a memória não é só de quem conta, o social se apropria dela, superpõe-lhe memórias oficiais. O testemunho oral nem sempre é mais autêntico do que a versão oficial, pode ser-lhe conivente. A memória é, segundo Ecléa (e não é difícil concordar) "cooptada por estereótipos que nascem, ou no interior da própria classe... ou de instituições dominantes como a escola, a universidade que são instâncias interpretativas da História" 
(p. 23). Ecléa sempre se mantém atenta ao que afasta o relato da realidade social, ofuscando-a. Denuncia a imposição sutil e perversa, que faz com que alguém veja os eventos sociais relevantes do modo como convém aos que detêm a mídia, o poder. "Quando um acontecimento político mexe com a cabeça de um determinado grupo social, a memória de cada um de seus membros é afetada pela interpretação que a ideologia dominante dá a este acontecimento. Portanto, uma das faces da memória pública tende a permear as consciências individuais" pp. 21-22).

Imagens, sentimentos, idéias e valores "politicamente corretos" alimentam a memória da pessoa e dão permanência às relações de classe e às explicações cômodas em termos das vantagens proporcionadas a alguns. Há alienação em relação à autenticidade afetiva. "O burguês, enquanto agente e produto do universo de valores de troca, não pode refugiar-se autenticamente na esfera da intimidade afetiva, pois até mesmo os seus objetos biográficos podem converter-se - e freqüientemente se convertem - em peças de um mecanismo de reprodução de status" (p. 29). O mecanismo é perverso, uma vez que convence inclusive a quem prejudica: "cada indivíduo pensa que é um caso à parte quando opina: mas ele acentua a sua particularidade enqua nto exalta o poder que o alienou" (p. 124).

O que também me preocupa é degradação da experiência no que ela tem de pessoal e de crítico. Estamos na era da informação excessiva. Tão distribuída é a atenção que ela se torna superficial e incapaz de constituir os esquemas pelos quais nos é dado integrar os conteúdos parciais do conhecimento. Além disso, a mídia aposta naquilo que atrai a atenção de forma fugaz, no nível suficiente para a elevação pontual de índices de audiência, gera modas que passam, assuntos de que as pessoas falam mas que esquecem muito rapidamente. Trata-se de ganhar de outro canal, de outro programa e a destreza na arte da competição vale mais do que o cuidado pelo conteúdo transmitido. A divulgação banaliza os crimes, os atentados, as guerras e até a miséria. Vivemos mergulhados numa informação descartável e numa instabilidade de atitudes e de posicionamentos que nos torna presas para o marketing, ele bem estruturado. 
"Uma história de vida não é feita para ser arquivada ou guardada numa gaveta como coisa, mas existe para transformar a cidade onde ela floresceu" (p. 69). Em frases como esta que encontramos amiúde no livro, se expressa o engajamento que Ecléa não considera posterior à démarche científica, mas como intrínseca a ela, sua motivação e seu guia. A história oral não é apenas o recolhimento do testemunho pessoal, ela é uma maneira de resgatar "as camadas da população excluídas da história". Há mais do que curiosidade científica no ato de dar a palavra a alguém.

No mínimo, a denúncia. $\mathrm{O}$ artigo sobre o campo de Terezin, na então Tchecoslováquia, que eu já tinha tido a oportunidade de ler na Revista Estudos Avançados do Instituto de Estudos Avançados da USP, não foi elaborado a partir de depoimentos diretos, mas o modo como Ecléa conta esta incrível história, o seu uso de relatos indiretos, de documentos e de imagens a tornam tão concreta como se ela tivesse ouvido os fatos da própria boca dos protagonistas (um fato deveras difícil uma vez que a maioria destas pessoas não sobreviveu à sua estada em Theresinstadt).

O que se denuncia, além da crueldade nazista, é o uso do disfarce e da mentira, da propaganda na pior acepção. Para tranqüilizar a opinião pública já bastante inquieta a respeito do destino dos judeus, quando já estava adiantado o processo de sua eliminação, organizam os ministros do Führer em meados de 1944 uma visita de membros da Cruz Vermelha à cidade de Terezin, na verdade um campo do qual partiam centenas de pessoas para o extermínio. Encontram os visitantes uma cidade limpa, dirigida por judeus, com orquestras e corais, atividades esportivas, jardim de infância moderno, enfim, "uma cidade normal de província" da qual os habitantes se apresentavam sorrindo e a respeito da qual davam depoimentos positivos. Todos, evidentemente, sabiam o que sofreriam caso se desviassem deste roteiro de bom comportamento.

Vale a pena ler o texto de Ecléa a respeito. Escrito como se fosse um documentário, deixa a emoção transparecer ao invés de escancará-la, permite ao leitor se expor à atmosfera de ameaça e discriminação, sentindo-a por conta própria. É um testemunho do quanto pode se dobrar alguém, quando 
humilhado ao extremo, mas também de impressionante valentia na afirmação dos valores e da vida. Escreve Ecléa: "Terezin concentrou em si uma terrível beleza. A resistência à 'banalidade do mal' se apresentou em formas expressivas na música, na pintura, no teatro, na poesia... mas também houve uma arte subterrânea, de denúncia" (p. 95). E cita um comovente exemplo de esperança: "Em 1943, o campo viveu um memorável acontecimento: a apresentação do Requiem de Verdi. Quando a quase totalidade do coral foi deportada.... lentamente se formou um segundo conjunto que pôde apresentar outra vez o Requiem... Mas, havendo novas deportações, os cantores se foram. Os sobreviventes do campo de Terezin formaram então um terceiro coral que, no outono de 1944, se apresentou para cantar o Requiem de Verdi" (p. 104).

O enraizamento é um dos conceitos de Simone Weil que Ecléa examina, mas de uma forma tão integrada ao próprio pensamento, quase sem aspas, que o leitor pode não perceber a passagem: "O ser humano tem uma raiz por sua participação real, ativa e natural na existência de uma coletividade que conserva vivos certos tesouros do passado e certos pressentimentos do futuro" (p. 75). Esta fórmula que diz tudo é de Simone Weil. Eu interpreto o enraizamento a partir da idéia mais ampla da integração dos seres vivos ao ambiente, uma idéia que permeia a biologia e que coloca os indivíduos e o seu contexto (o seu nicho) como partes interativas num sistema que a história evolutiva integrou. Daí que não se entende plenamente a vida de um animal enquanto não for considerada a maneira como este animal se insere, pelas características anatômicas e pela atividade funcional, no ambiente em que sobrevive. Tirar um animal de seu ambiente natural é por à prova a sua capacidade de adaptação ao ponto eventual do estresse e da ameaça à sobrevivência.

Também não entenderemos o ser humano se não prestarmos atenção à sua inserção no seu contexto principal, que é social. O grupo representa mais do que o conjunto de oportunidades a partir das quais se concretizam as ações individuais, ele é a matriz na qual a individualidade se estrutura e na qual se desenvolvem as ações significativas da pessoa, efetuadas no espírito de pertencer e de participar. "Hiroshima, c'est ton nom" diz ao amigo japo- 
nês a personagem central de L'Année Dernière à Marienbad, de Alain Resnais. E ele responde: "Oui, c'est mon nom. Ton nom à toi, c'est Nevers" e ambos recuperam assim, recuando no tempo, sua identidade primordial.

Terminarei esta resenha (que mais do que uma reflexão sobre a mensagem de Ecléa é uma reflexão de sua mensagem) com lembranças e uma árvore, uma figueira. As lembranças remontam às aulas de Psicologia Experimental que tivemos como alunos de uma das primeiras turmas de Psicologia da Faculdade de Filosofia, Ciências e Letras. Era no início da década de 1960, não há como esconder as datas, não é? O curso dispunha de algumas salas, num belo prédio tradicional (o antigo Palacete Jorge Street) da alameda Glete, esquina com a rua Guaianazes, onde os cursos da Geologia, da História Natural e da Química também funcionaram. Descíamos alguns degraus - era o porão do prédio - e entrávamos numa sala com uma mesa central, ao redor da qual cabia toda a turma, eram poucos os alunos ! para aulas sobre percepção, aprendizagem, psicologia comparativa. Alí, soubemos das idéias dos gestaltistas Koffka, Köhler, Lewin e também nos iniciamos na Etologia com Tinbergen e Lorenz. A sala, assim como outras menores, serviam de laboratório, no final do corredor foi instalado o sauveiro do Professor Walter Hugo de Andrade Cunha, onde, nos tubos e panelas de vidro, as formigas nos deixavam admirados com o seu incessante labor. Sentados à mesa de seminário, em reuniões à parte que marcávamos à noite, Walter, Arno Engelmann e eu discutíamos o modelo teórico de Miller, Galanter e Pribam, tal como exposto no livro Plans and the Structure of Behavior, em prenúncio do cognitivismo. Fernando Leite Ribeiro, Katsumaza Hoshino, Alcides Gadotti e eu lá planejamos um experimento sobre mapas cognitivos em ratos, de inspiração tolmaniana, só muito mais tarde realizado. Em duas salinhas, instalei um biotério improvisado e o meu primeiro laboratório, no qual fui investigando com curiosidade a natureza do comportamento exploratório. O espaço era pouco mas extraordinária a densidade de idéias, não nos abandonava um instante o senso de conquista intelectual. Há muito mais a dizer sobre a Glete como origem do que hoje são linhas de ensino e pesquisa no Instituto de Psicologia, mas deixemos isso para outro depoimento. Quero evocar o portão com uma guarita por onde entrávamos na Glete, e a bela figueira que 
ficava, na extremidade do pátio, perto do muro, expandindo seus galhos e sua folhagem para fora, formando uma cobertura para a calçada.

No começo dos anos 1970, sem motivo válido, atingindo a memória que lá se encontrava, foi destruído o palacete para dar lugar a um estacionamento de carros. Mas sobrou a figueira, fui visitá-la, há carros por toda a volta, mas ela ainda está bela e frondosa e o pessoal do estacionamento sabe que alí esteve, um dia, a Faculdade.

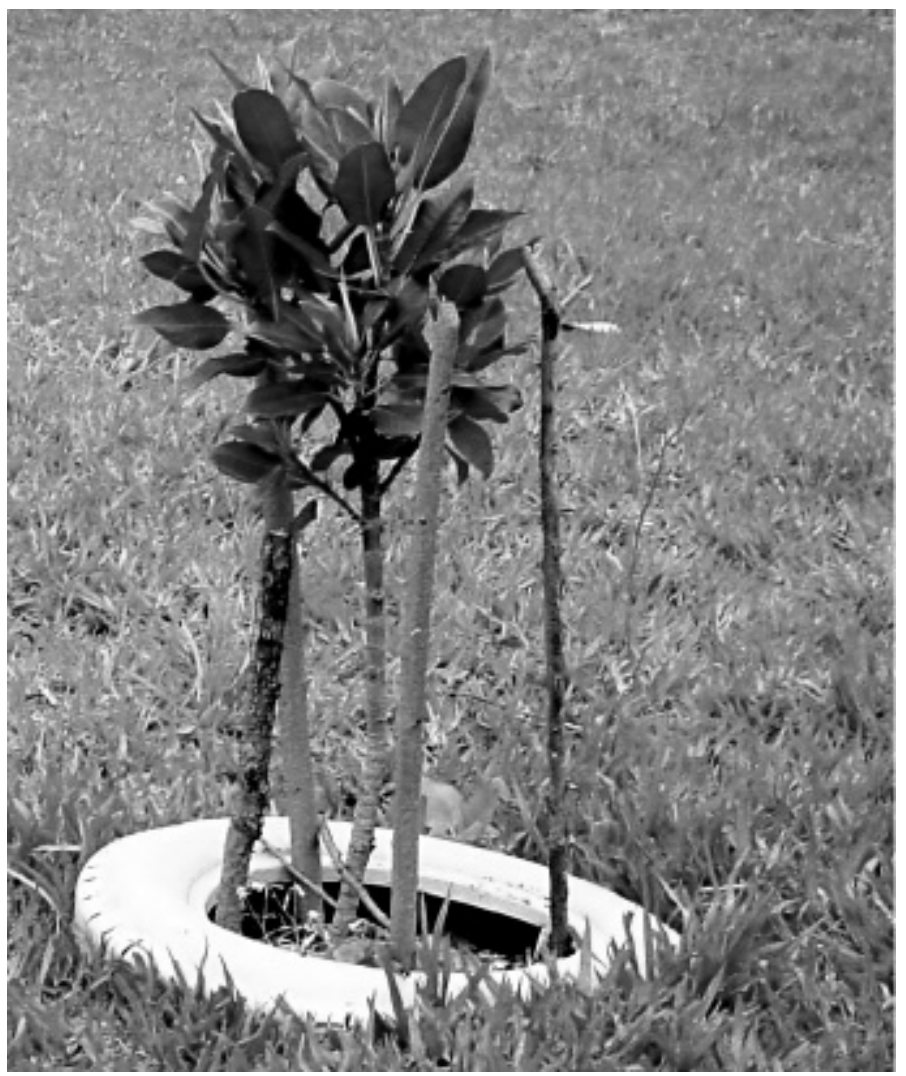

FIGUEIRA DA GLETE (Figueira das Geociências, 21.11.2003), um broto, memória viva. 
E um dia, recebi mensagens e, depois, a visita de uma pessoa notável, que é Neuza Guerreiro de Carvalho, da turma de 1951 de História Natural, na Glete. Portanto, gletiana (glettiana?) de primeira linha. Vovó Neuza tem batalhado para recuperar a memória da Glete, contactando e reunindo os exalunos dos diversos cursos, em torno da figueira, agora um símbolo. Colegas geólogos, em trinta de maio do ano passado, plantaram, frente ao Instituto de Biociências, onde está agora, verde, vicejando, um broto da figueira da Glete. Outro broto da figueira ainda há de crescer nos gramados do nosso Instituto, como marco de memória e de identidade. Como raiz.

\author{
César Ades \\ Instituto de Psicologia - USP
}

\title{
Referências
}

Bosi, E. (1999). O campo de Terezin. Estudos Avançados, 13(37), 7-32. Dossiê Memória

Bosi, Ecléa. (2003). O tempo vivo da memória: ensaios de psicologia social. São Paulo: Ateliê Editorial.

Dunbar, R. (1996). Grooming, gossip and the evolution of language. London: Faber and Faber.

Márquez, G. G. (2002). Vivir para contalar. Bogotá: Editorial Norma. 